\title{
El humor y el dolor: una simbiosis paliativa en Virus tropical de PowerPaola
}

Virus tropical (2009), de Paola Gaviria (n. 1977), artista gráfica nacida en Ecuador, criada en ese país y en Colombia y conocida como PowerPaola, retrata la dinámica familiar y los conflictos en su infancia y adolescencia. Al utilizar el humor en esta autobiografía, la artista logra mitigar lo que percibe como un efecto doloroso. Este artículo explora, con la ayuda de teorías sobre el humor y el dolor, la representación del cuerpo humano como el espacio donde el gozo y el sufrimiento pueden reconciliarse. Con la fuerza de la ilustración la artista refleja sentimientos humanos contradictorios y ofrece lecciones de vida desde la perspectiva distintiva del humor.

Palabras clave: Novela gráfica, humor, dolor, PowerPaola, autobiografía

Virus tropical (2009), by Paola Gaviria (b. 1977), a graphic artist born in Ecuador, raised in that country and Colombia, and known as PowerPaola, portrays family dynamics and conflicts during her childhood and adolescence. By using humor in this autobiographical work, the artist manages to mitigate what she perceives as a painful experience. Employing theories of humor and pain, this article explores the representation of the human body as a space where joy and suffering can be reconciled. The artist uses the power of illustration to reflect on contradictory human emotions and to offer life lessons from a distinctive and humorous perspective.

Keywords: Graphic novel, humor, pain, PowerPaola, autobiography

Virus tropical de Paola Gaviria, dibujante y escritora colombo-ecuatoriana también conocida como PowerPaola, cuenta la vida de su protagonista Paola desde su gestación y crecimiento en el vientre materno hasta su reconocimiento, ya como persona adulta, que está preparada para "salir al mundo" (159). La primera edición salió a la luz en 2009, y desde entonces se han publicado nuevas ediciones y traducciones al inglés, francés, italiano y otros idiomas. ${ }^{\text {E }}$ En 2017 , fue llevada a la gran pantalla como un filme de animación dirigido por Santiago Caicedo y producido por Carolina Barrera.

REVISTA CANADIENSE DE ESTUDIOS HISPÁNICOS 43.I (OTOÑO 2OI8) 
Su estreno tuvo lugar en el "Animation Is Film Festival", entre el 20 y el 22 de octubre de 2017 , en Los Ángeles.

A través de la novela gráfica Virus tropical, PowerPaola refleja sentimientos, contradicciones, injusticias y sinsabores de Paola, alter ego de la autora, durante su crecimiento y desarrollo como mujer. Mediante el uso de un lenguaje visual, los trazos sencillos convierten estas vivencias en lecciones de vida que le confieren a la historia un valor agregado fundamental. Este artículo propone una lectura del componente gráfico, por cuanto los dibujos conforman una dimensión donde el humor y el dolor dialogan y hacen de Virus tropical una historia cuya profundidad sobrepasa la narración coloquial de la vida de una familia. Se explora principalmente la representación del cuerpo humano como espacio donde el humor y el dolor convergen y se reconcilian. Así pues, se identifican rasgos y particularidades que expresan y sustentan la simbiosis propuesta, así como la habilidad de la autora para convertir sus trazos en un agente terapéutico contra las traumáticas huellas del pasado y, de esta manera, construir una historia más humana, amable y divertida. ${ }^{2}$

La novela gráfica ha experimentado en el siglo XXI un auge tal que la ha posicionado en un nivel mucho más prominente en la jerarquía literaria del que tuvo durante el siglo pasado. El desarrollo del género se puede trazar desde el surgimiento de los cómics underground de finales de los sesenta y comienzos de los setenta, difundidos principalmente a través de las ciudades universitarias. Esta clase de cultura de la narrativa gráfica, ahora dirigida a adultos y con poca o ninguna conexión con superhéroes, se caracteriza por manejar la sexualidad explícitamente y establecer un espacio donde ningún tema es tabú. Con este punto de viraje del cómic se propicia la base fundacional de lo que para finales de los ochenta se conocería como novela gráfica. En The Graphic Novel. An Introduction, Jan Baetens y Hugo Frey establecen: "[T] he underground comix invented formats and contents for future graphic novels, and then their own slow death presented a cultural-economic gap to be filled, albeit over the course of several years" (59). Es dicho espacio el que facilitó el florecimiento de obras como las de Art Spiegelman, particularmente Maus, la cual surgió de una colección underground, tan provocativa como el mismo underground comix. El espíritu subversivo, diferente y serio pero encasillado en "a comic about the Holocaust" (65), generó la necesidad de una etiqueta para estos trabajos que excedían las condiciones preestablecidas para los cómics. La misma zona, tanto temporal como discursiva, provee el ambiente propicio para el trabajo (auto)biográfico que Spiegelman desarrolló en su momento y que, a su vez, se distingue en mujeres caricaturistas cuya obra irrumpe a 
partir de los setenta, tales como Aline Kominsky, Dianne Noomin o Doris Seda. En su artículo "Perspectivas de la niñez adulta: El cómic como espacio de denuncia desde la marginalidad de sus personajes", Ana Merino argumenta que el trabajo de estas artistas se ve marcado muchas veces por un "existencialismo sórdido que alude en muchos casos a la pérdida de la inocencia sexual" ( 158 ). La tendencia a incluir el tema de la sexualidad se advierte y es ejemplificada en generaciones posteriores de mujeres entre las que se destacan la americana Phoebe Gloeckner, la canadiense Julie Doucet y la iraní Marjane Satrapi, quienes se convierten en modelos a seguir.

Por su parte, la inserción de la novela gráfica latinoamericana en el género de las historietas o cómics, cuyo público se limitaba a los niños o a lectores de segunda clase o no académicos, la mantuvo alejada del canon literario, situación que Ana Merino expone como derivada de la actitud de algunos académicos. En su artículo "Entre el margen y el canon: Pensamientos discursivos alrededor del cómic latinoamericano", Merino identifica un distanciamiento entre las culturas canónicas y los productos culturales como la historieta, así como la existencia de relaciones confusas entre los desconocedores del campo y los innovadores de los cómics latinoamericanos. Estos últimos veían las historietas como parte de la cultura del pueblo que, dada "la incapacidad lectora de un tipo de intelectualidad que no sabe descifrar el lenguaje de la historieta" (Merino, "Entre el margen" I4), les había impedido su mejor y más justa valoración. La crítica recuerda que, para 1965, ya el argentino Héctor Germán Oesterheld había formulado el precedente conceptual de lo que hoy se llama novela gráfica, a la cual había bautizado como "historieta nueva" (Merino, "Entre el margen" 14). De hecho, es en Argentina donde se fragua y se consolida parte de la cultura del cómic en Latinoamérica. De acuerdo con Merino, “[d]e Argentina emanó una tradición historietística que transformó los parámetros del medio" ("Entre el margen" I6). Con lo anterior no resulta sorprendente que haya sido precisamente en la Argentina donde PowerPaola se iniciara como historietista, y que la evolución de su trabajo hacia la novela gráfica la haya posicionado como una de las representantes del género reconocidas dentro y fuera del ámbito hispanoamericano.

La novela gráfica es, en el dominio de la literatura, un género narrativo, a diferencia de las caricaturas y de los libros de historietas, en los cuales narrar o representar una historia no es el objetivo principal. En este sentido y con el fin de adelantar una cabal valoración de Virus tropical que no pretende desvirtuar otros medios gráficos pero que se hace necesaria dada la ausencia de una definición formal para este nuevo género narrativo, se consideran los cuatro niveles desde los cuales Baetens y Frey identifican 
algunas de las particularidades de la novela gráfica. La forma, el contenido, el formato de publicación y la producción y distribución constituyen los niveles propuestos. La forma considera el diseño de la página y la narrativa. Aun cuando las historietas pueden considerarse una narración, esta depende de la decodificación secuencial de un encuadre que entrelaza imágenes horizontal y verticalmente organizadas. La novela gráfica utiliza estas características pero las adapta con el fin de lograr estilos individuales y, más importante aún, busca alejarse de las convenciones, inclusive aquellas que definieron las caricaturas de los años sesenta y setenta. El contenido, por su parte, sienta la diferencia bajo la consideración del tema adulto y serio, en oposición a la fantasía y a los superhéroes de las caricaturas, y en ciertas oportunidades tiende a ser autobiográfico. En algunos casos, incluso maneja documentales, reportajes o temas históricos. En el nivel del formato de publicación, la novela gráfica se inclina a adoptar uno que se parezca más a la novela tradicional en cuanto a su tamaño, cubierta y número de páginas, buscando alejarse completamente del formato de serie común en las caricaturas, y en general manteniendo un tema único dado que los libros de historietas habitualmente contienen numerosos eventos e historias independientes. Así mismo, el nivel de producción y distribución ligado al nivel anterior, hace referencia a la importancia de la editorial y de las librerías que las publican y venden (Baetens y Frey 7-23).

En conversación con El tío Bernie para Entrecomics, PowerPaola confiesa que después de leer las novelas gráficas de Julie Doucet:

[M] empecé a dar cuenta de que había toda una posibilidad de narración que tenía que ver con dibujo y dije, Yo quiero hacer exactamente lo mismo. Siempre quise contar la historia de mi familia de alguna forma y no sabía cómo hacerlo en pintura, y la historieta me daba la posibilidad de contar y narrar la historia. (énfasis añadido)

Este enfoque que PowerPaola explora en el trabajo de Doucet, no solo le sirve como modalidad expresiva, sino que también representa una especie de autorización que se da a sí misma para reflejar, en su cuerpo y en el de los miembros de su familia, aquellas manifestaciones con las cuales busca transmitir el sentimiento y el impacto de la vivencia más que el evento mismo. Según PowerPaola:

A ella [Doucet] no le da vergüenza decir que se metía cocaína, y que sufría en Nueva York, y que sangraba. Y me encanta que no le dé vergüenza y me anima a mí a que no 
me dé vergüenza, porque no soy la única mujer que sangra. ¡Creo que a todas les pasa lo mismo! ("Entrevista con PowerPaola")

Al mismo tiempo, el cuerpo humano, que tiene fundamental importancia en el dibujo de Doucet, cobra un valor eminente en la obra de PowerPaola, en la cual la influencia de la caricaturista canadiense es indiscutible. La viñeta "Heavy Flow", la cual forma parte de la colección Lève ta jambe mon poisson est mort! (1993) de Doucet, en donde aparece Julie como monstruo gigante menstruando en medio de una calle en el centro de Montreal, se reproduce al estilo de PowerPaola en la viñeta de una página titulada "La adolescencia".3 Sin embargo, la representación del cuerpo aparece completamente diferente en las dos dibujantes. Mientras la transgresión y la violencia son temas dominantes en Doucet, en PowerPaola estos aparecen reemplazados por rasgos de docilidad y ternura. Según Frederik Byrn Køhlert, ese monstruo en que se convierte Julie referencia la suciedad e inestabilidad de una mujer menstruando, así como la pérdida del control sobre el cuerpo femenino por parte del hombre. Doucet se apropia de estos estereotipos y los exagera con el fin de reconfigurarlos como una imagen del empoderamiento femenino (Køhlert 25). En este sentido, PowerPaola conserva ciertas ideas y las reproduce de forma similar, pero no impone el conflicto de género ni la visión dada por el hombre sobre esos días del mes, como tampoco dirige su atención hacia una protesta agresiva. Por el contrario, la dibujante colombo-ecuatoriana alude al trance y a la desazón del paso de la niñez a la adolescencia, una especie de melancolía hacia esa época infantil que deja atrás y la expectativa que ofrece la nueva etapa de su vida.

Virus tropical se adscribe también a las obras de tipo autobiográfico debido a sus características histórico-narrativas, pues como afirma PowerPaola, su novela nace de los dibujos publicados en un blog colectivo argentino denominado Historietas reales. En dicho blog, conformado por veinte caricaturistas latinoamericanos, PowerPaola publicaba una viñeta a la semana para mantener la continuidad y el ritmo exigidos, y así descubre que su vida le proporcionaba el tema apropiado ("Vidas dibujadas"). En su libro On the Graphic Novel, Santiago García recuenta los procesos y protagonistas que han definido y recorrido el camino iniciado con los cómics y que han llevado a la novela gráfica. En esta revisión, García identifica la autobiografía como el elemento facilitador en el proceso de transformación de la historieta. Para él: "Autobiography, often in its most banal and exhibitionistic form, was the vehicle that set in motion the takeoff of alternative comics on their journey towards the graphic novel" (García 
I62). Esta función de la (auto)biografía se ve claramente en la estrategia que anticiparon caricaturistas como Spiegelman y Marjane Satrapi, quienes partieron de una serie de caricaturas agrupadas respectivamente en Maus (199I), una representación histórica-biográfica, y Persepolis (2000), una obra histórica-autobiográfica. En su análisis del trabajo de Harvey Pekar, figura influyente entre los historietistas que se arriesgaron a plasmar en su producción episodios difíciles de su pasado como Doucet, García establece que, "in autobiography, honesty was the main virtue, and there was no need for much in the way of formal development to bring all his power to the page" ( $16_{3}$ ). Al priorizar el contenido sobre el dibujo, García resalta el valor de la autobiografía en tanto tema. Obras como Clumsy (2002), de Jeffrey Brown, se caracterizan por una evidente falta de calidad en el dibujo, la cual le trajo problemas de publicación a su autor. No obstante, una vez publicada, resultó ser un éxito internacional de ventas dada la espontaneidad y cercanía con las que Brown transmitió sus experiencias. PowerPaola no solo maneja el tema autobiográfico honestamente, sino que, además, con un trazo sencillo pero lleno de expresión y matices, ratifica sus experiencias y esa fuerza narrativa de la que habla García.

En este sentido, la autobiografía deviene, entre otras cosas, un ejercicio práctico de definición del Yo, en el que se intenta verificar experiencias y comportamientos del pasado importantes en el proceso de desarrollo del individuo. De acuerdo con Francisco Rodríguez en su análisis sobre "las primeras reflexiones teóricas" (13) en el estudio de la autobiografía del filósofo alemán Wilhelm Dilthey: "[l]a tarea de la autobiografía consiste en intentar elaborar un yo, que es el reemplazo construido por la memoria de aquel que en realidad vivió los hechos que se recuerdan" (15). Desde este punto de vista, en Virus tropical, el nuevo Yo de PowerPaola describe los eventos de acuerdo con los recuerdos que de ellos tiene la autora:

[Virus tropical e]s ciento por ciento autobiográfica. Obviamente que al narrarse uno mismo termina siendo ficción, porque si le preguntas a mi hermana, por ejemplo, tiene otra idea de lo que fue nuestra familia o de la relación con nuestro padre. Cada persona arma su historia a su antojo, pero para mí esta es ciento por ciento real. ("El 'superpower' de Paola")

Lo anterior, incorporado al componente gráfico que amplifica la significación del texto solo, ofrece una posibilidad de lectura centrada en detalles de un alto contenido narrativo y expresivo. Así como James Kochalka, a partir de una tira cómica diaria basada en un evento de su vida, logra convertir hechos cotidianos que, aislados, no resultan significativos 
pero unidos "[become] a fully realized portrait of my life" (García I63), PowerPaola crea una novela en donde la dinámica del núcleo familiar se reproduce a través del recuento de sucesos importantes de su niñez y adolescencia. De esta manera, narra una historia universal en un contexto local, ya sea ecuatoriano o colombiano, pero en todo caso latinoamericano.

La descripción de vivencias familiares desbroza el camino que llevará a PowerPaola a ser una dibujante. La autora lo reconoce al afirmar: "[a]1 trabajar con mi propia vida como tema en mi trabajo, el dibujo ha sido un instrumento vital para ser consciente de cómo vivo, siento, pienso" (PowerPaola, "Entrevista personal"). En el caso de Virus tropical, gracias a la honestidad con la cual describe a los miembros de su familia, al uso de vivencias cotidianas, a la presentación de un ambiente que despliega la historia sin salir de sus fronteras geográficas pero conservando una trama cercana a lectores de sociedades más diversas y a la calidad de su trazo, la novela resulta especialmente atractiva para el lector. La dimensión gráfica, por su parte, añade detalles de acuerdo con las preferencias de PowerPaola: "me gusta que las imágenes hablen por sí solas" (PowerPaola, "Entrevista personal"). En tal sentido, la universalidad de las vivencias le ofrece al lector la posibilidad de identificarse con experiencias o comportamientos de los personajes. De igual manera, PowerPaola afirma que, en Virus Tropical:

[M] uestro mis partes negativas, no solo las de mi familia. En cierto momento me di cuenta de que no estaba solamente de mí [sic], que estaba hablando de la gente, y no me parecía tan mal. Cuando lo fueron leyendo mis papás y mis hermanas, a pesar de que había cosas que les daban un poco de vergüenza, se sintieron contentos. Porque sintieron que lo estaba haciendo con cariño, en ningún momento había reproches o insultos. ("Entrevista con PowerPaola")

Esta confesión refleja cómo esos hechos que configuraron el Yo de Paola se corresponden con la experiencia de PowerPaola y su familia, en un hogar signado por la presencia de la madre y la ausencia del padre. La referencia al sentimiento de vergüenza por parte de los miembros de la familia ante la publicación de algunos episodios que pueden parecer bochornosos, tales como el abandono paterno o los melodramas de la madre, ejemplifica el carácter personal de la narración.

Aun cuando la lectura de esta novela gráfica puede verse influida no solo por sus rasgos culturales, sino además por las experiencias de formación de su individualidad, PowerPaola afirma a propósito de la recepción de su obra: 
Cuando yo empecé a hacer Virus Tropical, nunca imaginé que tuviera tanta repercusión y siento que a pesar de las particularidades de los lugares la gente se identifica con situaciones que vivió parecidas. Todos crecemos más o menos de la misma manera. En Italia, España, Francia y Estados Unidos [la novela] ha sido bien recibida. ("Entrevista personal")

El hecho de que la novela haya tenido una acogida bastante amplia fuera de Colombia y Ecuador, y en sociedades de muchas maneras disimiles entre sí, podría explicarse a partir de la definición de Carl Gustav Jung sobre los arquetipos, en particular, el proceso cerebral que los activa.4 Según Jung, en The Basic Writings of C. G. Jung, el inconsciente colectivo se asienta en un nivel profundo del subconsciente:

The unconscious does not derive from personal experience, and is not a personal acquisition but is inborn. This deeper layer I call the collective unconscious ... because this part of the unconscious is not individual but universal; in contrast to the personal psyche, it has contents and modes of behavior that are more or less the same everywhere and in all individuals. It is, in other words, identical in all men and thus constitutes a common psychic substrate of suprapersonal nature which is present in every one of us... The contents of the collective unconscious ... are known as archetypes. (299-300)

Los arquetipos a los que hace referencia Jung, como centros neurológicos, tienen la capacidad de iniciar, controlar y mediar entre características del comportamiento común y experiencias típicas del ser humano. Por lo tanto, aún cuando las situaciones pueden presentarse con rasgos particulares, como es el caso de Virus tropical, en circunstancias apropiadas, los arquetipos generan en el cerebro pensamientos, sentimientos e ideas similares independientemente de la raza, localización geográfica, clase, credo o época histórica.

De igual manera, el hecho de que Virus tropical ofrezca una historia muy local y al mismo tiempo muy universal obedece a la habilidad de PowerPaola de convertir, a través del dibujo, las experiencias de vida en lecciones enriquecedoras. Para ello, la dibujante introduce aspectos de la cultura latinoamericana en detalles muy concretos. Un primer ejemplo de esto es el tinto, el café en taza pequeña que forma parte de la costumbre colombiana de beberlo a cualquier hora del día. La representación de Chavela, la empleada doméstica, se caracteriza por hacer referencia a la infusión casi todo el tiempo. En la viñeta titulada "La religión", que más adelante se analizará con detenimiento, la empleada doméstica parece 
ofrecer un tinto a Uriel, el padre de Paola. Así mismo, la propia Chavela sugiere otro factor cultural interesante. Considerada una integrante más de la familia, disfruta de toda la confianza de Hilda, la madre de Paola. Sin embargo, cuando se presenta la oportunidad, roba dinero a la señora de la casa. Hilda, leyéndose a sí misma el dominó, descubre el hurto por lo cual pide a Chavela que le deje ver la cartera. La actitud de la señora de la casa se presentaba con cierta frecuencia en Colombia dado que, comúnmente, si se daba la oportunidad y debido a los bajos salarios de las empleadas domésticas, estas tomaban dinero o pertenencias de la casa. La perspicacia con la cual la dibujante incorpora el recuento del robo, al convertir la lectura del dominó en el medio informativo del mismo y al anunciar los resultados de la interpretación en globos de burbujas con Chavela como protagonista, se reafirma en la manera como la misma Chavela se libra de la posible pérdida de su trabajo. En medio del drama del robo, Hilda tiene una discusión con la hija mayor, y Chavela, arrodillada y llorando, aprovecha para traer a colación la infusión salvadora, "Doña Hilda, ¿Le hago un tinto?", a lo cual Hilda responde, "Sí, gracias Chavela" (54). De esta manera el robo del dinero pasa al olvido.

En Virus tropical, en esta operación creativa que se le atribuye al dibujo, las imágenes complementan el evento específico al que quiere llegar PowerPaola. Baetens y Frey, en su estudio de la novela gráfica, argumentan: "What is essential in the graphic novel is that drawing is less a technique that is used to shape a given story than a creative operation that produces the images and the very stories themselves" (I64). De esta manera, cada viñeta aporta detalles gráficos fundamentales al sentido global que recrea la historia, esta última más cercana a cómo la autora y su familia la vivieron, pero particularmente a cómo la autora la recuerda. A su vez, el texto, en su carácter de elemento complementario pero que es en sí mismo dibujo dado que se construye a través de trazos, se integra de igual modo y en forma natural. Por lo tanto, su localización, ya sea en la página, en la viñeta, en los globos o en la caja de comentarios, cobra un valor importante. Las palabras están allí no solo para ser leídas, sino para ser miradas en conjunto con las imágenes y en relación con su lugar en la novela. En este discurso visualizado, en el que cualquier trazo conlleva un significado, la posición de las viñetas en las páginas y la de éstas en el libro merecen especial atención. Benoît Peeters, en "Four Conceptions of the Page", define cuatro modalidades de uso de las viñetas, entre ellas, la "rhetorical utilization", en la cual "the panel and the page are no longer autonomous elements; they are subordinated to a narrative which their primary function is to serve. The size of the images, their distribution, the general pace of the page, all must 
come to support the narration" (I9). Virus tropical hace uso de este tipo de comunicación gráfica y, si bien no se observa una variación muy grande en las dimensiones de las viñetas (alrededor de seis tamaños diferentes), tampoco se mantiene un mismo patrón de organización o diseño en cada página.

PowerPaola, recurre a viñetas de una página para enfatizar y apoyar la narración y, en algunas de ellas, el discurso escrito alcanza la complejidad sintáctica indispensable para reflejar el evento. El texto ahora pasa al primer plano exigiendo la total atención del lector y un acercamiento más pausado y reflexivo. Un ejemplo de esta particularidad se advierte en una viñeta (PowerPaola, Virus I23) donde se representa la reunión familiar alrededor de la mesa y, especialmente, la reacción de la madre a la noticia de Uriel a la pérdida de todos los ahorros familiares por una mala inversión de su parte. Hilda aparece rodeada de ocho balones de texto que revelan sus quejas y su rol de madre sufrida:

¿Y ahora qué vamos hacer [sic], Uriel? / ¿Cómo nos vamos a mantener? / Uriel, no podemos seguir viviendo en la misma casa ... ya no estamos casados ... / Es que ustedes no saben lo que es ser una madre / ...Y a mí me ha tocado sola. Uriel nunca ha estado en momentos difíciles... / Paola cambió conmigo desde que nos vinimos a vivir a Colombia / Yo le advertí a Claudia que no se casara con Juan Carlos, pero a mí nadie me hace caso / Patty...Ya casi toda una psicóloga y quiere ser la mamá de Paola. (I23)

Los balones ocupan una gran área en la viñeta y su distribución y tamaño claramente reflejan la diatriba de Hilda, así como su posición ante la crisis económica y afectiva en la familia. Es claro que no asume responsabilidad alguna sobre los hechos al inculpar a los demás miembros de la familia de su propia desgracia. La imagen predominante de la madre que parece hablar desde un nivel superior, resalta más allá de su conflicto personal, la actitud pasiva que ha caracterizado a Uriel como padre. Así mismo, la aglomeración de los balones y la falta de espacio para comentarios informa sobre la imposibilidad, por parte de los demás miembros de la familia, de manifestar sus opiniones. Con el manejo de la perspectiva y del texto la autora impregna la viñeta de particularidades que sustentan el valor intrínseco de su dibujo pero que primordialmente, narran un evento con todo el valor sentimental que conlleva pero sin olvidar el toque lúdico que siempre se encuentra de alguna manera involucrado.

En Virus tropical, los trazos y el manejo apropiado de las herramientas que ofrece la novela gráfica resaltan la importancia de ciertas experiencias 
en la vida de PowerPaola en las que, un espectro de representaciones corporales le permite entremezclar el dolor y el humor e integrar este último al contexto en el que ubica su historia y la de los miembros de la familia. La viñeta que abre la novela (fig. I) corresponde al momento de la concepción de Paola. Se trata de un recuadro divertido donde se fija el inicio de su vida y de una historia, que de otra manera no existiría. El dibujo mismo, así como el tamaño de la viñeta, suministran información y precisan algunas de las características de los padres en cuanto a su personalidad y a su historia afectiva. De esta manera, su representación y su entorno, en esta particular situación, se ocupa menos de sus características físicas y más de la relación entre ellos. Predomina el distanciamiento afectivo y el trato frío entre la pareja, dada la separación de los cuerpos y la seriedad con que se miran. Él, aún portando sus gafas, y ella, con una mirada sumisa pero inexpresiva, anticipan el desarrollo ideo-temático de la novela: una relación en la cual el esposo no asume su papel y la esposa no exige explicaciones al respecto. No hay ningún elemento en la presentación de los cuerpos de los padres de PowerPaola que permita pensar en un matrimonio feliz. El hecho mismo de ubicarlos sobre una mesa, en lugar de una cama, pone de manifiesto una relación mecánica y casi inexorable para los dos. Del mismo modo, los objetos que los rodean dan pistas sobre sus roles en la familia. El sentimiento del padre, quien se mantiene muy ligado todavía a la religión a pesar de su decisión de abandonar el sacerdocio, se evidencia en la Biblia debajo de la silla y la pistola que apunta a la cruz del rosario. La dirección de la pistola podría sugerir el asesinato de su vida sacerdotal. El dominó, como herramienta de trabajo de la madre y fuente temporal de ingresos de la familia, se localiza muy cercano al billete que, a su vez, permanece asido a la mesa donde se lleva a cabo la gestación de Paola, esto último como indicativo de los problemas que traerá consigo el descuido y mal manejo del dinero por parte del padre. Más adelante, como ya se mencionó, es claro que el padre no ayuda económicamente a la familia; son primero la madre y luego las hijas las que proveen el sustento de la casa.

Desde el momento de la gestación hasta el momento del parto, PowerPaola crea un escenario donde los personajes se mueven entre la incertidumbre y el dolor. El embarazo indeseado, los diagnósticos errados de los médicos y la ilusión de que fuera un varón ambientan la llegada de Paola. El malestar que genera el descubrir las condiciones del nacimiento puede resultar traumático; sin embargo, la autora desvía esta incomodidad rodeando a los personajes de elementos graciosos. De esta manera enfrenta su historia y, según aclara ella misma, recurre al cariño como una fórmula de acercamiento a su pasado. La autora reconoce que busca minimizar el 
efecto que pueda causar su novela en los miembros de su familia. En este sentido, el embarazo no planeado de la madre se transforma en una serie de comentarios cómicos con los cuales los médicos tratan de explicar la imposibilidad de la concepción, puesto que la madre se había sometido a una intervención quirúrgica para no tener más hijos. Para algunos doctores, el creciente abdomen de Hilda se debía a un "virus tropical", a un "virus ecuatorial", un "embarazo psicológico" o simplemente era "aire" (PowerPaola, Virus 9). Basándose en imágenes y textos en globos que expresan las opiniones populares, esta situación se vuelve divertida e intrascendente. Según la historietista: "[e]s verdad que el comic me aligera, me hace bien. Es la única manera que he encontrado para entenderme a mí misma ... Pero es una necesidad, no es algo que yo haga porque quiero mostrar, sino porque necesito entenderlo" (PowerPaola, "Entrevista con PowerPaola"). La necesidad a la que hace referencia la caricaturista se explica desde el humor "Self-enhancing" el cual, "involves a generally humorous outlook on life, a tendency to be frequently amused by the incongruities of life, and to maintain a humorous perspective even in the face of stress adversity ... the use of humor as an emotion regulation or coping mechanism" (Rush 39). 5 Es este elemento defensivo el que se impone particularmente en aspectos complejos en los que PowerPaola recrea el recuerdo que de ellos conserva. En este sentido, las circunstancias dramáticas aparecen en nexo estrecho con el dolor, pero este queda solapado en un nivel menos evidente al dar paso a los aspectos lúdicos que aportan el pretendido valor curativo.

Aunque no se trata de una novela cómica, los detalles juguetones más bien se insinúan recreando un ambiente a través del cual se representa la trama sin ofensas hacia los protagonistas. Esta hipótesis se apoya fundamentalmente en los estudios sobre el dolor de David Morris. En su libro The Culture of Pain, Morris afirma: "The modern world employs pain with a detachment that reflects our need to distance ourselves from affliction at the same time we are fascinated by it and put it to multiple uses" (I82-83). El distanciamiento autoimpuesto de PowerPaola y la fascinación que le produce recrear su vida conforman, en última instancia, el sentido del dibujo y del texto. En la sección "La familia" se refiere la visita de la abuela Doña Teresa, quien llega a la casa para conocer a su nueva nieta. La representación de la cara de Paola en la viñeta (PowerPaola, Virus I9) hace palpable el dolor que siente cuando enfrenta el momento en que su abuela le abre los huecos en las orejas. Una vez que Doña Teresa termina su trabajo, Paola aparece llorando. Aquí el dolor no se manifiesta con la onomatopeya del llanto de la niña, sino con lágrimas y expresiones que destacan la triste 
realidad. El texto de la viñeta enfatiza específicamente que "[l] os huecos no quedaron a la misma altura" (ig). Esta dimensión del humor conlleva en sí misma la presencia del dolor en la medida en que los mecanismos de defensa surgen para enfrentar situaciones incómodas. La molestia ocasionada por el error de la abuela se contrarresta con la perspectiva en el dibujo con la que la autora presenta este episodio de la vida de Paola. La desproporción de la cabeza, que ocupa casi toda la viñeta, con una hinchazón bastante pronunciada, la boca pequeña y torcida, los ojos minúsculos, un número diferente de lágrimas en cada ojo y, por supuesto, los aretes desnivelados conjugan de forma efectiva el dolor de la experiencia con lo cómico de su representación.

Del mismo modo, PowerPaola parece conectar directamente la figura de Doña Teresa con su función de producir dolor a sus nietas. La dibujante la presenta como una mujer con una nariz larga, un cuerpo escuálido y una mirada malévola que en ningún momento tiene una actitud cariñosa hacia las nietas. El inconformismo de la abuela por el matrimonio de su hijo, a quien había enviado al seminario cuando tenía once años, es evidente en los comentarios críticos en relación con la crianza de Paola por parte de Hilda. La madre de Uriel utiliza las caídas de Paola, representadas mediante las protuberancias accidentales en la cabeza de la niña, como una forma de resaltar la inutilidad de Hilda como madre. Dada la maldad que muestra la abuela al tomar el anillo de matrimonio de Hilda e insinuarle a Uriel que esta se lo quita cuando sale de la casa, con un carácter florido, PowerPaola revive el episodio en que sus dos hermanas y Chavela, encerradas en el baño, se comen los chocolates de la abuela para mortificarla por el dolor que causó a la madre con esas acusaciones. En tres viñetas aparecen las niñas y Chavela atiborrándose de chocolates, acción que se resalta exagerando cómicamente el tamaño de los pómulos y la hartura de las tres (PowerPaola, Virus 2I-22).

El límite entre Uriel como padre de familia y Uriel como sacerdote y miembro de la Iglesia católica es muy difuso. Como cabeza de familia, es más oficiante que esposo o padre dada su indeterminación entre el ministerio sacerdotal y la vida laica. Esta amalgama parece tener bastante relevancia en la infancia de Paola. En la cultura latinoamericana, en particular en la colombiana de la población del departamento de Antioquia donde nació el padre, era típico que al menos un miembro de la familia perteneciera al clero. Paola lo recuerda: "[e]ra el orgullo de las familias paisas* tener un hijo sacerdote" (PowerPaola, Virus I8). ${ }^{6}$ La religión fue siempre un punto crítico en la dinámica familiar, un motivo de conflicto no sólo para la abuela, sino también para Hilda, dado el comportamiento frío y distante de su esposo y 
hacia las niñas, para quienes el padre fue mayoritariamente una figura pasiva y lejana en el hogar. "Tengo pocos recuerdos de mi papá en mi infancia" (PowerPaola, Virus 33), dice Paola. Sin embargo, las experiencias con el padre cobran una importancia trascendental en su vida. Por sus insuperados conflictos, a Uriel le resultaba casi imperativo seguir ejerciendo sus actividades sacerdotales incluso dentro de la casa. Paola recuerda que: "[d]e manera clandestina mi papá daba misa los domingos en la casa" (PowerPaola, Virus 28). En la sección asignada a la religión, la dibujante representa estas anécdotas casi increíbles. En la primera viñeta de la sección aparece el padre en la mitad de la sala con el cáliz en la mano y dando la eucaristía a una de sus hijas, mientras otra de las hermanas muy cerca lee una revista con las piernas cruzadas y la madre observa desde una esquina (28).

Si bien PowerPaola deja claro que no buscaba darle a Virus tropical un carácter humorístico, este se puede argumentar, a partir de los estudios de Luigi Pirandello. En El humorismo, para Pirandello, el humorista: "descompone el carácter de su personaje en sus diferentes elementos; y mientras que aquel otro [un poeta épico o dramático] se preocupa de captarlo coherentemente en cada una de sus actuaciones, éste se divierte en representarlo con sus incongruencias" (I53). Las experiencias religiosas en la infancia de Paola son precisamente eso: una relación de sucesos sin una lógica. Aunque fue Uriel quien impulsó a Paola a hacer un dibujo para entregárselo al Papa en el aeropuerto cuando este llegara a Ecuador, dos días antes del encuentro, posiblemente el más importante en la vida de la niña hasta ese momento, el padre decide abandonar la casa. La experiencia se torna aún más traumatizante cuando Paola no logra entregarle su dibujo al sumo pontífice.

El humor en el cual se inscribe la representación del cuerpo en Virus tropical, los gestos, las contorsiones $\mathrm{y}$, con cierta frecuencia, las más abyectas funciones corporales sirven para establecer un balance entre el humor y el dolor. Por ejemplo, el acto de expeler gases por parte del padre de Paola, al cual ella hace referencia enfáticamente, "huele a pedo" (PowerPaola, Virus 33), es una seña cómica del malestar no solo corporal sino también emocional que experimenta la protagonista en relación con su padre y que se puede explicar desde la perspectiva del cuerpo cómico. En este sentido Morris afirma: "[t]he possession of a body absolutely guarantees the comic prerequisite that sooner or later something will go wrong, often painfully wrong" (8I). Este aspecto que resulta dolorosamente equivocado es en sí el conflicto religioso al que se enfrenta la familia de Paola, representado en el cuerpo del padre. Ese mundo irreal donde habita 
Uriel lo lleva a imponer unos preceptos religiosos bastante desviados del ejercicio espiritual. Desde esta óptica, los gases corpóreos neutralizan la tensión de Uriel con su familia y ofrecen el elemento lúdico que completa la imagen que de él tiene su hija.

Para el sociólogo Anton Zijderveld, el humor "allows people to become aware of the constructedness of social life itself: humor is a 'looking glass' allowing us to look at the world and ourselves in a slightly distorted, and hence revealing, way" (Citado en Kuipers 376). Este "looking glass" que para la autora está representado en cada uno de los trazos de las viñetas, valida su forma particular de presentar los eventos. El toque jovial se transforma así en elemento de distorsión para enfrentar esa realidad de su pasado y, de paso, asimilar la desnaturalización de ese mundo devoto y la actitud caricaturesca de su padre. Según Morris, “[o]ur bodies also provide a fundamental source and object of human laughter" (82). Es decir, el cuerpo de Uriel no solo mueve a la risa como reacción a su comportamiento, sino que también ofrece una imagen cómica en sí mismo, lo cual queda plasmado en la viñeta de una página (PowerPaola, Virus 26), en la que éste aparece parado en la biblia, con un rosario en las manos y en actitud de oración, pero a su vez expeliendo gases.

La decisión de la dibujante de iniciar cada sección con una viñeta del tamaño de la página, con la representación del cuerpo de su protagonista, va más allá de una simple coincidencia al formar parte de ese lenguaje único articulado en su dibujo. De acuerdo con Baetens y Frey, los dibujos no se reducen a simples ilustraciones porque completan y matizan el texto con información visual (I47). Así pues, en el trabajo de PowerPaola, las expresiones faciales y, sobre todo, la perspectiva y el tamaño cumplen dicha función complementaria. La viñeta que introduce el tema de la religión, (fig. 2), presenta a Uriel sentado en un trono con su investidura sacerdotal, un libro en una mano (posiblemente la Biblia) y en la otra una hostia. En la parte inferior, a la derecha, se halla su familia: Hilda señalándolo mientras se dirige a sus hijas y Paola con actitud miedosa y escondida detrás de sus faldas mientras sus hermanas mayores parecen atender al discurso de la madre. A la izquierda y en un nivel un poco más inferior se ve a Chavela, como siempre, ofreciendo el tinto. Las proporciones del dibujo hablan por sí solas. La figura hiperbólica de Uriel, tres veces más grande, la posición a todas luces inferior de las cinco mujeres, con aspecto más de observadoras, como venerando forzosamente una estatua religiosa, describen el papel dominante de la religión y la percepción que Paola tiene del lugar de las mujeres en la jerarquía en el hogar. El recurso para entender la dinámica familiar se puede explicar desde el enfoque de Sigmund Freud en Jokes and 
Their Relation to the Unconscious en torno a la parodia: "Parody ... achieve[s] the degradation of something exalted in another way: by destroying the unity that exists between people's characters as we know them and their speeches and actions, by replacing either the exalted figures or utterances by inferior ones" (249). Ya se ha mencionado que PowerPaola no pretende con Virus tropical hacer un juicio sobre ninguno de los miembros de su familia, pero resulta inevitable la alusión paródica. El tamaño de los cuerpos es inversamente proporcional al rol en la familia de cada uno de sus integrantes pero directamente proporcional a su compromiso religioso. Bajo esta lectura, es evidente que el comportamiento de Uriel como padre se degrada en la medida en que su interés religioso se impone en el dibujo.

El carácter temático de las viñetas introductorias en cada sección, como se ha dicho, en particular su referencia al protagonista principal, ofrece otra técnica desde la cual se acentúa la particularidad del trazo de PowerPaola. En la viñeta "Las despedidas" (fig.3), Hilda se enfrenta al hecho de que sus hijas mayores abandonan la casa en busca de su propia vida, sin lugar a duda una de las circunstancias más dolorosas para una madre. Varios aspectos cobran nuevamente gran valor en el recuento gráfico de esa experiencia por parte de PowerPaola. El tamaño de las figuras coadyuva a una lectura del impacto emocional de estas despedidas. El llanto de la madre, quien ocupa el mayor espacio en la viñeta, representa la magnitud de la pena. Su dolor suscita un valle de lágrimas a donde van a entrar inevitablemente sus dos hijas mayores, representado a través de la hipérbole de un mar lacrimoso. El edificio, en tanto metonimia de su hogar, parece resultar ileso pero deshabitado. Por su parte, el padre deviene simple espectador, con el agua al cuello, alegoría del posterior ahogo económico al que someterá a la familia. Se intuye que Hilda se encargará de mantener a flote a la familia. Paola, muy pequeña y aún bajo la tutela de la madre, aparece resguardada en un bolsillo del abrigo de ella, protegida del agua y registrando cada detalle. Desde su posición es testigo de la partida de las hermanas pero muy particularmente del impacto que la vivencia tiene en Hilda, explicado por PowerPaola en el sobredimensionado melodrama de la madre. Es obvio que la salida de las hijas altera la vida de la madre, sin embargo, no se debe olvidar el efecto doloroso en la pequeña Paola, quien se cuestiona con tristeza al final de la sección: “¿Cómo hace la gente para entender el mundo si no tiene hermanas mayores?" (PowerPaola, Virus 7I). Dado que las relaciones afectivas y el proceso de maduración de Paola se articulan sobre la base de la interacción entre las hermanas, aunque la madre ejerce un papel fundamental en su infancia, son aquellas quienes asumen la labor de padre y madre en varias etapas de su vida. El antídoto que le procuran el 
ingenio y la comicidad destacados en la minuciosa exposición de las expresiones en los rostros y cuerpos de las hermanas cayendo del edificio como resultado de la sacudida que le asesta Hilda a la construcción llevan su sufrimiento, ya claramente identificado, a un segundo plano en donde la autora se ofrece a sí misma esa acción terapéutica.

PowerPaola revaloriza su experiencia en la niñez y, especialmente, en la adolescencia dando cuenta de actos rebeldes en contextos donde sale a relucir la ausencia de sus padres en momentos cruciales de su desarrollo. De acuerdo con Norman Holland en Laughing. A Psychology of Humor, a pesar de que "[c]omedy vents our rebellious spirits, much the most common idea about comic catharsis is that comedy teaches us the worldly wisdom of acceptance" (90). De esta forma, la dibujante, por medio de ese proceso de purificación que ofrece la comedia, acepta sana y positivamente el comportamiento de sus progenitores. En ese mismo sentido, el gramático Donato argumenta que: "[c] omedy is a story of various habits and customs of public and private affairs, from which one may learn what is of use in life and what must be avoided" (citado en Holland 9I). La opción sugerida por Donato añade un sentido aún más valioso al humor dado que ofrece un marco comparativo del cual se pueden desprender acciones positivas.

La sección "La identidad" (PowerPaola, Virus II3) se abre con una viñeta donde aparece Paola adolescente. Esta representación somática ofrece una imagen autorreferencial de PowerPaola misma, incluidos sus aspectos físicos y conflictos personales. Varios detalles de su apariencia y ciertos elementos del dibujo llaman la atención. El corte de cabello, una gorra con el símbolo de la paz, un brazalete en la parte superior del brazo, un arete grande con forma de animal (tal vez una cabra), una argolla pequeña en la oreja y unos patines, completan el perfil de la Paola independiente y rebelde en la que se convierte. Del mismo modo, la dibujante incorpora la tentación simbolizada por un pequeño diablito colgando del cabello y el amor incorporado con un cupido. Se distinguen, además, sus útiles de trabajo e incluso una libélula volando cerca de su cabeza. Si se presta atención a ciertas creencias populares, una interpretación de la libélula tendría que ver con la conexión de este insecto con el carácter individual debido a que, "[l]a libélula, en casi todas las partes del mundo, simboliza el cambio en la perspectiva de la auto-realización, la madurez mental, emocional y la comprensión profunda del significado de la vida" ("Libélulas"). De todos estos detalles, que la dibujante añade cuidadosamente, se desprende el conflicto que la joven enfrentaba en su momento. Con el uso de la perspectiva como herramienta discursiva, ahora Paola no es esa pequeña niña asustada, sino una adolescente cuya cabeza ocupa el primer plano y 
que se impone sobre el resto del cuerpo. De manera similar, a la descripción convencional de su crecimiento físico, la autora añade el dilema que enfrenta de joven cuando muchos aspectos de la vida resultan inciertos.

En efecto, como argumentan Baetens y Frey: "[l]anguage in the graphic novel is always just half of the story: good language and good drawing are never enough; it is the interplay between words and images that has to work" (I49). El hecho de que el título de la viñeta "La identidad" se encuentre en proceso de construcción, dado que sus últimas letras aparecen aún en el suelo y sin diseño definido, precisa esa interacción entre palabras e imágenes que permite transmitir el estado anímico de Paola. La severidad narrativa en la representación gráfica de Paola se ve matizada por los rasgos cómicos e inquietos que les dan a los incidentes en esta etapa de su vida, esencialmente difíciles (apenas aparecen referencias a momentos positivos y menos espinosos), una tonalidad conmovedora que permite reconocer una experiencia propia no solo de su familia, sino también, por sinécdoque, de la clase media, particularmente en Colombia donde PowerPaola vivió desde la adolescencia.

Como se ha visto a través del artículo, uno de los valores intrínsecos de la novela gráfica yace en la combinación efectiva del dibujo y el texto, principio que se sigue de cerca en Virus tropical. En particular, en los temas referidos y en general, en la novela, la conexión entre palabras y dibujos ofrece el ambiente propicio para relativizar el drama sin perder su sentido $\mathrm{y}$, en última instancia, conducir a una historia donde las experiencias traumáticas se diluyen con un humor sencillo, aunque representativo de la dinámica familiar. Como PowerPaola subraya: "[t]odos tenemos que tomar ciertas decisiones en ciertos momentos, y permitirse cometer errores en la vida está bien" ("Entrevista personal"). En el caso particular de Virus tropical, la representación corporal le ofrece la oportunidad a la autora de enunciar gráficamente el sentido y valor de cada uno de los miembros de su familia y de las relaciones entre ellos. Al mismo tiempo, por medio de los aspectos lúdicos, se permite completar ese proceso paliativo, resultado de la conjugación dolor-humor, que, como lo afirma David Morris, únicamente se puede llevar a cabo en el cuerpo humano. Cabe agregar que el dolor cómico no se reduce al universo de la novela, pues la comicidad apela también a las vivencias dolorosas del lector, no exento de lastres existenciales. Esta comunión del dolor y del humor contribuye a procesar la realidad desde una perspectiva más reposada y proactiva, que lleva a aceptar la experiencia como una instancia del pasado y a asumir los errores como parte del proceso de crecimiento personal. Ninguna de las vivencias de Paola adquiere visos de melodrama; por el contrario, se convierten en 
formas de aprendizaje y aceptación. De su estancia en París, donde descubrió el gran potencial de la historieta y donde surgió su nombre artístico, recuerda la dibujante: "[m]e aproveché de ese nuevo nombre [PowerPaola] ... y me dediqué a dibujar. Con ese nombre me inventé una Paola valiente, una que podía con todo" (Camacho Iannini). De esta manera, esa niña que, desde el momento de la concepción hasta la edad adulta, se mantiene indagando y cuestionándose su personalidad y, globalmente, su propio discurrir vital, ofrece sus vivencias que no pertenecen solo a la artista, sino además a todos los lectores $\mathrm{y}$, ahora, al público que se acerca a la versión fílmica de la novela.

University of Florida

NOTAS

I Para este artículo se usa la edición del 20I4 publicada por La Editorial Común.

2 Dada la variada gama de modalidades estéticas del humor y la complejidad de sus diferentes significados y denominaciones, cuyo estudio llevaría un análisis ajeno al objetivo de este artículo, cualquier mención a alguna de ellas debe entenderse desde su referencia al humor en general y no a una modalidad en particular.

3 Incluida en el artículo "Female Grotesques: Carnivalesque Subversion in the Comics of Julie Doucet” de Frederik Byrn Køhlert.

4 No se consideran las definiciones más particulares acuñadas por Jung, tales como el arquetipo de la madre, más orientado al estudio de la imagen de la madre, tema que va más allá del alcance de este estudio.

5 Martin et al. (2003), en su investigación sobre los estilos de humor "adaptive" y "beneficial", en oposición a los "maladaptive" y "malignant", argumentan que éstos deben ser estudiados desde dos diferentes componentes, uno relacionado con el humor interpersonal (dirigido hacia los otros) y otro, el intrapersonal enfocado más hacia sí mismo. Como resultado identifican cuatro dimensiones distintas del humor a saber, "affiliative", "self-enhancing", "aggressive" y "self-defeating".

6 El asterisco corresponde al pie de página, por medio del cual PowerPaola aclara el significado de "paisa", gentilicio de los nacidos en Antioquia, un departamento de Colombia. 
OBRAS CITADAS

B A et ens, JA N, And hugo fRey. The Graphic Novel. An Introduction. New York:

Cambridge UP, 2015.

CAMACH o iannini, SERgio. "Power Paola, la historietista que dibuja su vida." El

Tiempo. I4 mayo 20I4. S. pag. Web.

FREU D, SI G M U N D. Jokes and Their Relation to the Unconscious. Trad. James Strachey.

New York: W. W. Norton \& Company, I989.

ga Rcía, San tiag o. On the Graphic Novel. Trad. Bruce Campbell. Jackson: UP of

Mississippi, 2015.

H O L LAN D, N ORM A N N. Laughing. A Psychology of Humor. Ithaca: Cornell UP, 1982.

JUnG, CAR L G. The Basic Writings of C. G. Jung. Trad. R.F.C. Hull. Princeton: Princeton

UP, 1990 .

KøHLERT, FREDERIK в. "Female Grotesques: Carnivalesque Subversion in the

Comics of Julie Doucet." Journal of Graphic Novels and Comics 3.I (2012): 19-39.

Web.

KUIPERS, GISELINDE. "The Sociology of Humor." Raskin: 36I-98.

"Libélulapedia. Mitos y realidades sobre las libélulas." Libélulas.

Enciclopedia especializada. S. pag. Web.

MARTIN, ROD A., ET AL. "Individual Differences in Uses of Humor and their

Relation to Psychological Well-being: Development of the Humor Styles

Questionnaire." Journal of Research in Personality 37.I (2003): 48-75. Web.

MER IN O, ANA. "Entre el margen y el canon: Pensamientos discursivos alrededor del cómic latinoamericano." Revista Iberoamericana 77.234 (2011): 13-18.

—. "Perspectivas de la niñez adulta: El cómic como espacio de denuncia desde la marginalidad de sus personajes." IC - Revista Científica de Información y Comunicación 7 (2010): 149-167.

MOR IS, DAVID B. The Culture of Pain. Los Angeles: U of California P, I993.

PE E TE RS, B EN OîT. "Four Conceptions of the Page." Trad. Jesse Cohn. ImageTexT.

Interdisciplinary Comics Studies 3.3 (2007): I-66.

PI RAN D Ll o, Luigi. El humorismo. San Lorenzo del Escorial: Bilingües de Base, 2007.

Po We r pa o la. "Entrevista con PowerPaola." El tío Berni. Entrecomics. I7 abr. 20Iz. S. pag. Web.

-. Entrevista personal. 22 octubre 2016.

—. "El 'superpower' de Paola." Entrevista de Janina Pérez Arias. Fucsia. S. pag. Web.

—. "Vidas dibujadas." Entrevista de Catalina Holguín. Arcadia. 5 marzo 20 Io. S. pag. Web.

—. Virus tropical. Buenos Aires: La Editorial Común, 20I4. 
RASkin, VICT OR, ED. The Primer of Humor Research. Berlín: De Gruyter Mouton, 2008.

ROD Rí G U E Z, F RA NCISCO. "El género autobiográfico y la construcción del sujeto autoreferencial." Filología y Lingüística 26.2 (2000): 9-24.

RUCH, WILlibALD. "Psychology of Humor." Raskin: I7-IOo. 
ANEXOS

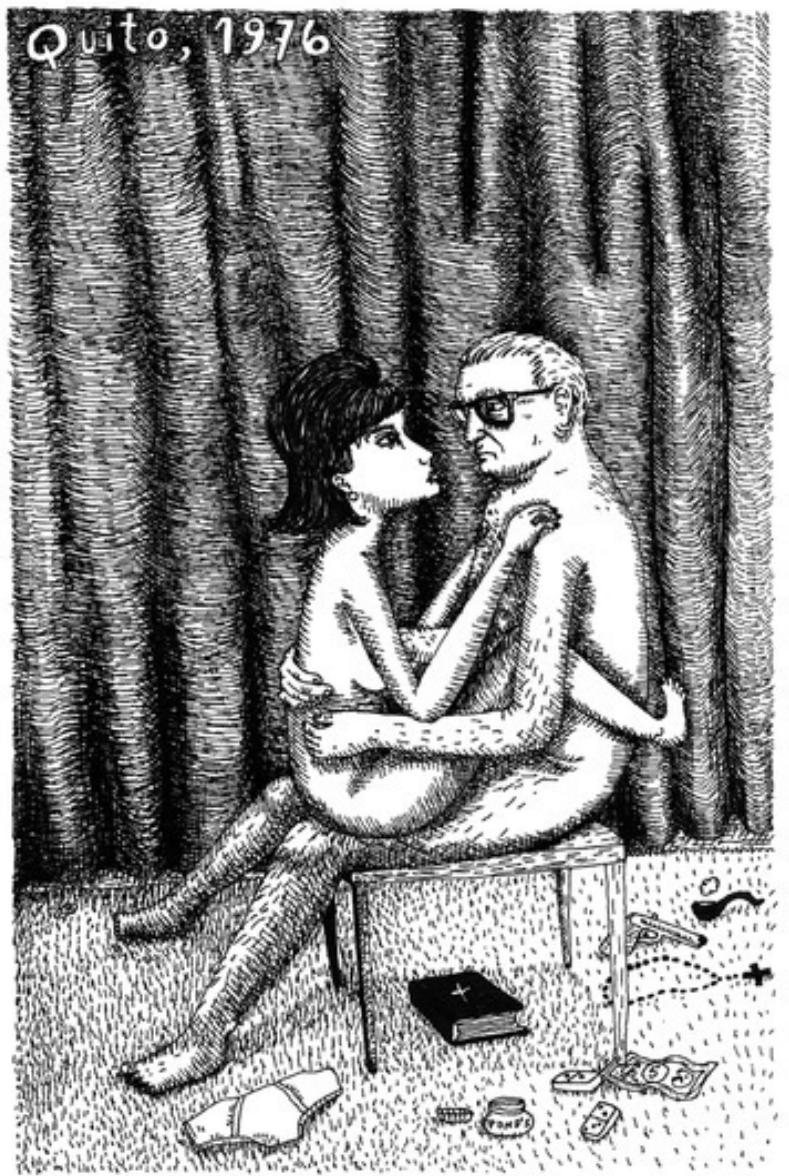

5

Figura I 




Figura 2 


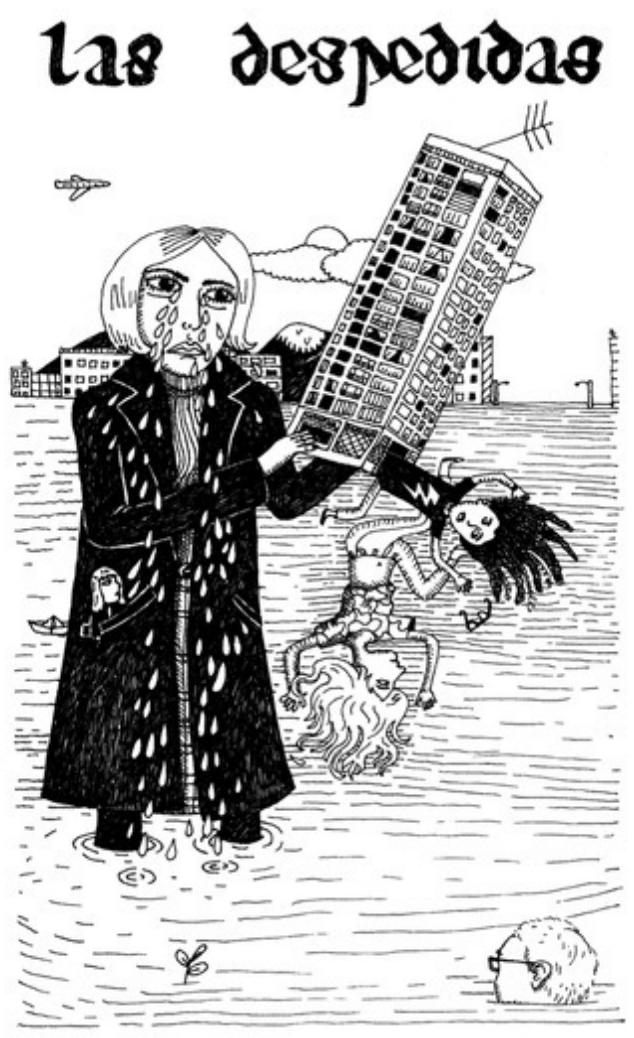

Figura 3 